\title{
Dominating Role of Ionic Strength in the Sedimentation of Nano-TiO 2 in Aquatic Environments
}

\author{
Guang'an He, ${ }^{1}$ Rui Chen, ${ }^{1}$ Shushen Lu, ${ }^{1}$ Chengchun Jiang, ${ }^{2}$ Hong Liu, ${ }^{1,3}$ and Chuan Wang ${ }^{3}$ \\ ${ }^{1}$ School of Chemistry and Chemical Engineering, Sun Yat-sen University, Guangzhou 510275, China \\ ${ }^{2}$ School of Civil and Environmental Engineering, Shenzhen Polytechnic, Shenzhen 518055, China \\ ${ }^{3}$ Chongqing Institute of Green and Intelligent Technology, Chinese Academy of Sciences, Chongqing 400714, China
}

Correspondence should be addressed to Hong Liu; liuhong@cigit.ac.cn

Received 31 July 2015; Accepted 27 September 2015

Academic Editor: Lutz Mädler

Copyright (C) 2015 Guang'an He et al. This is an open access article distributed under the Creative Commons Attribution License, which permits unrestricted use, distribution, and reproduction in any medium, provided the original work is properly cited.

\begin{abstract}
Various factors affect the sedimentation behavior of nanotitanium dioxide $\left(\mathrm{n}-\mathrm{TiO}_{2}\right)$ in water. Accordingly, this study aimed to select the dominating factor. An index of sedimentation efficiency related to $\mathrm{n}-\mathrm{TiO}_{2}$ concentration was applied to precisely describe the $\mathrm{n}$ $\mathrm{TiO}_{2}$ sedimentation behavior. Ionic strength (IS), natural organic matter (NOM) content, and $\mathrm{pH}$ were evaluated in sedimentation experiments. An orthogonal experimental design was used to sequence the affecting ability of these factors. Furthermore, simulative sedimentation experiments were performed. The $\mathrm{n}-\mathrm{TiO}_{2}$ sedimentation behavior was only affected by $\mathrm{pH}$ and NOM content at low levels of IS. Moreover, divalent cations can efficiently influence the $\mathrm{n}-\mathrm{TiO}_{2}$ sedimentation behavior compared with monovalent cations at fixed IS. Seven different environmental water samples were also used to investigate the $\mathrm{n}-\mathrm{TiO}_{2}$ sedimentation behavior in aquatic environments. Results confirmed that IS, in which divalent cations may play an important role, was the dominating factor influencing the $\mathrm{n}-\mathrm{TiO}_{2}$ sedimentation behavior in aquatic environments.
\end{abstract}

\section{Introduction}

As nanotechnology rapidly progresses, nanotitanium dioxide $\left(\mathrm{n}-\mathrm{TiO}_{2}\right)$, a promising engineered nanomaterial, has been extensively used in different fields, such as manufacturing industries [1], environmental protection [2-5], and consumer products $[6,7]$. The inevitable release of $\mathrm{n}-\mathrm{TiO}_{2}$ in the environment may result in its easy suspension in air, transport through water, or settling in soil. Hence, acquiring $\mathrm{n}-\mathrm{TiO}_{2}$ through dermal, ingestion, and inhalation routes may pose a high risk to humans and other organisms because of its potential harms [8-12].

Environmental behavior, including dispersion, transportation, aggregation, and sedimentation, of $n-\mathrm{TiO}_{2}$ has been considerably investigated [13]. Most studies focus on determining the effect of $\mathrm{pH}[14,15]$, ionic strength (IS) $[16,17]$, and natural organic matter (NOM) content [18-20] on the sedimentation behavior of $\mathrm{n}-\mathrm{TiO}_{2}$. These factors are important water indexes in an actual aquatic environment and can be easily evaluated by using well-controlled synthetic water in the laboratory. Nevertheless, the dominating factor remains unclear.

To determine the dominating factor, we included four important stages in our experimental strategy. The individual effect of each single factor on $\mathrm{n}-\mathrm{TiO}_{2}$ sedimentation behavior must be first investigated. Then, an orthogonal experimental design, known as systematic method, which has been applied in different fields, such as physical science [21], chemical engineering [22], ecology, and biotechnology, is used to sequence the affecting ability of these factors and their interactions. After statistical analysis, further simulative sedimentation experiments should be performed to determine and confirm the dominating factor. Finally, several sedimentation experiments must be conducted using water samples from different representative aquatic environments to provide practical and intuitive evidence and thus confirm the important role of the dominating factor.

In this study, we used concentration instead of particle size of $\mathrm{n}-\mathrm{TiO}_{2}$ as the criterion to evaluate its sedimentation 
behavior. We also proposed the index of sedimentation efficiency (SE) with the following formula:

$$
\mathrm{SE}=\frac{\left(c_{0}-c_{t}\right)}{c_{0}} \times 100 \%,
$$

where $c_{0}$ is the initial concentration of $\mathrm{n}-\mathrm{TiO}_{2}$ and $c_{t}$ is the concentration of $\mathrm{n}-\mathrm{TiO}_{2}$ after sedimentation. An orthogonal experimental design $\left[\mathrm{L}_{27}\left(3^{13}\right)\right]$ of $\mathrm{n}-\mathrm{TiO}_{2}$ sedimentation was applied. In this design, it contained twenty-seven tests, three levels, and thirteen factors. Among these thirteen factors, they consisted of three independent factors $(\mathrm{pH}, \mathrm{IS}$, and NOM), six relevant factors (two for interactions between $\mathrm{pH}$ and IS, two for interactions between $\mathrm{pH}$ and $\mathrm{NOM}$, and two for interactions between IS and NOM), and four blank factors which were used to calibrate the orthogonal experimental system. This experimental strategy is a new attempt to study the sedimentation behavior of $\mathrm{n}-\mathrm{TiO}_{2}$ and thus may provide an alternative method to evaluate the environmental behavior of other nanoparticles in the future.

\section{Materials and Methods}

2.1. Chemicals. The commercial $\mathrm{n}-\mathrm{TiO}_{2}$ (99.8\% metal basis, $25 \mathrm{~nm}$, anatase, hydrophile, dry powders) was purchased from Aladdin Industrial Corporation (China). The transmission electron microscope (TEM) images (see Figure S1 in Supplementary Material available online at http://dx.doi.org/ $10.1155 / 2015 / 851928$ ) and X-ray diffractometer (XRD) patterns (Figure S2) confirmed the product parameters got from the manufacturer that the original size of $n-\mathrm{TiO}_{2}$ was $25 \mathrm{~nm}$ and crystal form of $\mathrm{n}-\mathrm{TiO}_{2}$ was anatase. All inorganic reagents were acquired from Guangzhou Chemical Reagent Factory (China). Fulvic acid (FA) was also obtained from Aladdin Industrial Corporation, and humic acid (HA) was acquired from Jufeng Chemical Science and Technology Corporation (China). All reagents used in this study were of analytical reagent grade. The double-distilled water used in all experiments was generated using an ultrapure water system (Milli-Q, USA).

2.2. Preparation of Inorganic Salt and NOM Solutions. Six common inorganic salts $\left(\mathrm{NaCl}, \mathrm{KCl}, \mathrm{Na}_{2} \mathrm{SO}_{4}, \mathrm{~K}_{2} \mathrm{SO}_{4}, \mathrm{MgCl}_{2}\right.$, and $\mathrm{CaCl}_{2}$ ) were utilized in this study. Stock solutions with 1.0 M IS were prepared for each inorganic salt and were filtered through a $0.45 \mu \mathrm{m}$ syringe filter (Membrana, Germany). Two representative NOM (FA and HA) which were known to have high molecular weight and large molecular structure were employed in this study. Both FA and HA were dried at $105^{\circ} \mathrm{C}$ for $2 \mathrm{~h}$ and dissolved with $1 \mathrm{~mol} \mathrm{~L}^{-1} \mathrm{NaOH}$, and $1 \mathrm{~mol} \mathrm{~L}^{-1} \mathrm{HCl}$ was subsequently added to adjust the $\mathrm{pH}$ to 7.0. The stock solutions of FA and HA with $50 \mathrm{mg} \mathrm{L}^{-1}$ total organic carbon (TOC) concentration were also filtered through a $0.45 \mu \mathrm{m}$ syringe filter and stored in a refrigerator without light at $4^{\circ} \mathrm{C}$.

2.3. Preparation of Environmental Water Samples. Seven environmental water samples were evaluated in this study: (a) tap water from our laboratory at the Sun Yat-sen University (Guangzhou, China), (b) lake water (LW) from Haizhu Lake (Guangzhou, China), (c) river water (RW) from Pearl River (Guangzhou, China), (d) phreatic water (PW) from Daya Bay (Huizhou, China), (e) sea water (SW) from Nansha Beach (Guangzhou, China), (f) reservoir water (RE) from Mutouchong Reservoir (Zhuhai, China), and (g) waste water (WW) from the Luogang Waste Water Treatment Plant (Guangzhou, China). In a typical procedure, $5 \mathrm{~L}$ of each environmental water sample was placed into a $5 \mathrm{~L}$ amber reagent bottle to avoid light and stored for $24 \mathrm{~h}$ to separate the insoluble substance. Each environmental water sample was filtered through a $0.45 \mu \mathrm{m}$ syringe filter. Subsequently, $500 \mathrm{~mL}$ of the phreatic water sample was diluted with $5 \mathrm{~L}$ of deionized water to decrease its high salinity.

2.4. Characterization and Measurement. Organic elemental analysis, infrared radiation (IR) spectrum, ultraviolet-visible (UV-Vis) spectrum, and carbon analysis of FA and HA were measured with an elemental analyzer (VARIO EL CUBE, Elementar Analysensysteme $\mathrm{GmbH}$, Germany), Fourier transform infrared spectrometer (NICOLET AVATAR 330, Thermo Fisher, USA), UV-Vis spectrophotometer (TU-1810, Persee, China), and TOC analyzer (Multi N/C 3100 TOC/TN, Analytik Jena AG, Germany), respectively.

Common inorganic ion analysis, carbon analysis, $\mathrm{pH}$, and conductivity of the environmental water samples were measured using an ion chromatograph (ICS-900 and ICS5000, Dionex Thermo, USA), TOC analyzer (TOC-VCPH, Shimadzu, Japan), pH meter (PHB-3/pH, Shanxin, China), and conductivity detector (DDS-11A, Yulong, China), respectively.

TEM (TECNAI G2 SPIRIT, FEI, USA) images were obtained to observe the original size of $\mathrm{n}-\mathrm{TiO}_{2}$ and XRD (DMAX 2200 VPC, Rigaku, Japan) patterns were utilized to determine the crystal form of $\mathrm{n}-\mathrm{TiO}_{2}$. Moreover, an autotitrator (BI-ZTU, Brookhaven, USA) was used to determine the isoelectric point of $\mathrm{n}-\mathrm{TiO}_{2}$.

The $\mathrm{n}-\mathrm{TiO}_{2}$ suspension sampled in the sedimentation tube was placed into a $15 \mathrm{~mL}$ crucible and then vaporized on an $800 \mathrm{~W}$ electric stove (ES-0320, Triangle, China). The $\mathrm{n}-\mathrm{TiO}_{2}$ can be digested when it is melted with potassium pyrosulfate and becomes titanium sulfate. A stable yellow complex that can be detected by UV-Vis spectrophotometer is generated when acidic hydrogen peroxide is added. According to this property of the complex, we had established a detection procedure of $\mathrm{n}-\mathrm{TiO}_{2}$ concentration. In this procedure, $0.5 \mathrm{~g}( \pm 0.1 \mathrm{~g})$ of $\mathrm{K}_{2} \mathrm{~S}_{2} \mathrm{O}_{7}$ was added into the crucible and melted on the electric stove for $2 \mathrm{~min}$ until the suspension was completely evaporated. Subsequently, $3.0 \mathrm{~mL}$ $( \pm 0.1 \mathrm{~mL})$ of $10 \% \mathrm{H}_{2} \mathrm{SO}_{4}$ (volume fraction) was added into the crucible and heated on the electric stove for $1 \mathrm{~min}$ after the molten mixture cooled down. The solution was then placed into a $10 \mathrm{~mL}$ colorimetric tube and immediately added with $1.0 \mathrm{~mL}( \pm 0.1 \mathrm{~mL})$ of $30 \% \mathrm{H}_{2} \mathrm{O}_{2}$ (mass fraction). Deionized water was also added to dilute the solution into scale. After 5 min of coloration, the solution was subjected to a UVVis spectrophotometer at $400 \mathrm{~nm}$. And a standard curve (Figure S3) was used as the quantitative criterion of $n-\mathrm{TiO}_{2}$ 
TABLE 1: Factors and levels of the orthogonal experiment.

\begin{tabular}{lccc}
\hline Factors & \multicolumn{3}{c}{ Levels } \\
& 1 & 2 & 3 \\
\hline $\mathrm{pH}$ & 6.0 & 7.0 & 8.0 \\
$\mathrm{IS}(\mathrm{mM})$ & 0.5 & 2.5 & 25 \\
$\mathrm{NOM}\left(\mathrm{mg} \mathrm{L}^{-1}\right)$ & 0.5 & 1.0 & 5.0 \\
\hline
\end{tabular}

concentration because the linear correlation coefficient is close to $1\left(R^{2}=0.9999\right)$.

2.5. Orthogonal Experimental Design. An orthogonal experiment design $\left[\mathrm{L}_{27}\left(3^{13}\right)\right]$ was applied to determine the effect of three factors and their interactions on $\mathrm{n}-\mathrm{TiO}_{2}$ sedimentation behavior. In this design, pH, IS of the mixed inorganic salt solution, and TOC concentration of the mixed NOM solution as three factors were evaluated. Three levels were set in each independent factor (Table 1).

2.6. Sedimentation Experiments. Sedimentation experiments were conducted in sedimentation tubes (height: $30 \mathrm{~cm}$, radius: $2 \mathrm{~cm})$ for $4 \mathrm{~h}$. Briefly, $0.0250 \mathrm{~g}( \pm 0.0002 \mathrm{~g})$ of $\mathrm{n}-\mathrm{TiO}_{2}$ was weighed with an electronic balance (FA-1104, Hengping, China) and was added in each tube. Pretreated inorganic salt and NOM solutions or environmental water samples were subsequently added. The suspensions were immediately ultrasonicated in an ultrasonic generator (AS3120A, Autoscience, China) for $15 \mathrm{~min}$, and the initial $\mathrm{n}-\mathrm{TiO}_{2}$ concentration was $100 \mathrm{mg} \mathrm{L}^{-1}$.

The following eight different sedimentation experiments were conducted: (A) single factor experiment with $\mathrm{pH},(\mathrm{B})$ single factor experiment with IS, (C) single factor experiment with NOM content, (D) orthogonal experiment, (E) double factor experiment with IS of monovalent and divalent cations, (F) double factor experiment with $\mathrm{pH}$ and IS, (G) double factor experiment with NOM content and IS, and $(\mathrm{H})$ environmental water sample experiment. Solution conditions in each experiment were shown in Table 2.

In experiment $\mathrm{A}$, the $\mathrm{pH}$ of the suspension was adjusted from 1.0 to $13.0( \pm 0.1)$ with $1.0 \mathrm{~mol} \mathrm{~L}^{-1} \mathrm{HCl}$ and $\mathrm{NaOH}$. In experiments $\mathrm{B}, \mathrm{F}$, and $\mathrm{G}$, the $\mathrm{pH}$ was adjusted from 6.0 to 8.0 $( \pm 0.1)$ with $0.1 \mathrm{~mol} \mathrm{~L}^{-1} \mathrm{HCl}$ and $\mathrm{NaOH}$. In experiments $\mathrm{C}, \mathrm{D}$, and $\mathrm{E}$, the $\mathrm{pH}$ was adjusted to $7.0( \pm 0.1)$ with $0.01 \mathrm{~mol} \mathrm{~L}^{-1} \mathrm{HCl}$ and $\mathrm{NaOH}$.

In experiments D and G, the mixed NOM solution was prepared using FA and HA stock solutions with a mass ratio of $1: 1$. In experiments $D, F$, and $G$, the mixed inorganic salt solution with an IS ratio of $1: 1$ for monovalent cations and anions and for divalent cations and anions was prepared with $\mathrm{Na}_{2} \mathrm{SO}_{4}, \mathrm{~K}_{2} \mathrm{SO}_{4}, \mathrm{MgCl}_{2}$, and $\mathrm{CaCl}_{2}$ stock solutions. In experiment $\mathrm{E}$, the mixed inorganic salt solution with a $1: 1 \mathrm{IS}$ ratio of monovalent and divalent cations was prepared with $\mathrm{NaCl}, \mathrm{KCl}, \mathrm{MgCl}_{2}$, and $\mathrm{CaCl}_{2}$ stock solutions.

We immediately sampled $1.00 \mathrm{~mL}( \pm 0.01 \mathrm{~mL})$ of each suspension with a pipette at $1 / 4$ height of each sedimentation tube after $4 \mathrm{~h}$ of sedimentation. The concentration of $\mathrm{n}$ $\mathrm{TiO}_{2}$ was detected using a UV-Vis spectrophotometer. All
TABLE 2: The solutions conditions of the sedimentation experiments.

\begin{tabular}{ll}
\hline $\begin{array}{l}\text { Sedimentation } \\
\text { experiment }\end{array}$ & Solution conditions \\
\hline $\mathrm{A}$ & $\mathrm{pH}$ from 1.0 to 13.0 \\
\hline $\mathrm{B}$ & $\begin{array}{l}\text { Ionic strength of } \mathrm{KCl} \text { from } 0.01 \mathrm{mM} \text { to } 100 \mathrm{mM} \\
\text { Ionic strength of } \mathrm{CaCl}_{2} \text { from } 0.01 \mathrm{mM} \text { to } 15 \mathrm{mM} \\
\mathrm{pH}=7.0\end{array}$ \\
\hline & $\mathrm{TOC}$ concentration of $\mathrm{HA}$ from $0.5 \mathrm{mg} \mathrm{L}^{-1}$ to \\
& $10 \mathrm{mg} \mathrm{L}^{-1}$ \\
& $\mathrm{pH}=7.0$
\end{tabular}

sedimentation tests were performed in triplicate, and data in average were presented.

\section{Results and Discussion}

3.1. Characterization of NOM and Analysis of Environmental Water Samples. We determined the relative concentrations of $\mathrm{C}, \mathrm{N}, \mathrm{H}$, and $\mathrm{S}$ in NOM, and $\mathrm{C}$ was proven as the major element (Table $\mathrm{S} 1$ ). The relative $\mathrm{C}$ concentrations of FA and HA were $41.28 \%$ and $61.19 \%$, respectively. Total carbon, TOC, and inorganic carbon (IC) of NOM were further analyzed, and we found that the ratio of TOC/IC ranged from 12:1 to $15: 1$ (Table S2). Hence, TOC concentration, instead of the original concentration of NOM, was used in sequential n$\mathrm{TiO}_{2}$ sedimentation experiments. The IR and UV-Vis spectra presented in Figures S4 and S5 further confirmed the presence of many aromatic organics containing carboxyl and hydroxyl groups in NOM.

The results of analysis on common ions, $\mathrm{pH}$, conductivity, and carbon of environmental water samples were shown in Tables S3, S4, S5, and S6, respectively. The pH of all samples was approximately neutral. Phreatic water, sea water, and waste water samples contained high amount of inorganic ions, and their conductivities were high because of their high salinity. Moreover, waste water samples presented higher TOC concentration than any other sample. 
3.2. Sedimentation Experiments of $n-\mathrm{TiO}_{2}$ with Single Factor. Water composition is very complex in actual aquatic environments and is a crucial factor that governs the stability of nanoparticles and their mobility as colloidal suspension or their aggregation into larger particles and deposition [2325]. The effects of $\mathrm{pH}, \mathrm{IS}$, and NOM content on $\mathrm{n}-\mathrm{TiO}_{2}$ sedimentation behavior were evaluated in this study.

Figure $1(\mathrm{c})$ shows the $\mathrm{SE}$ of $\mathrm{n}-\mathrm{TiO}_{2}$ in different $\mathrm{pH}$ values. The $\mathrm{SE}$ of $\mathrm{n}-\mathrm{TiO}_{2}$ at $\mathrm{pH} 4.0$ was about $35 \%$ after $4 \mathrm{~h}$ sedimentation and higher than that at other $\mathrm{pH}$. This finding could be attributed to the nearness of the $\mathrm{pH}$ of the solution to the $\mathrm{pH}_{\mathrm{pzc}}$ of $\mathrm{n}-\mathrm{TiO}_{2}$. Fang et al. had found out that the point of zero charge $\left(\mathrm{pH}_{\mathrm{pzc}}\right)$ of commercial $\mathrm{n}-\mathrm{TiO}_{2}$ was 4.5 [26]. In this study, we had also measured the $\mathrm{pH}_{\mathrm{pzc}}$ of $\mathrm{n}-\mathrm{TiO}_{2}$ and the result was 4.21 (Figure S6). At pH 7.0, the $\mathrm{SE}$ of $\mathrm{n}-\mathrm{TiO}_{2}$ was about $20 \%$, which was the lowest. The $\mathrm{SE}$ of $\mathrm{n}-\mathrm{TiO}_{2}$ began to increase at $\mathrm{pH}<7.0$ or $>7.0$. The zeta potential of $n-\mathrm{TiO}_{2}$ also demonstrated a similar pattern (Figure S6). It can be revealed that a high zeta potential will confer stability; when the zeta potential is low, attraction exceeds repulsion, and the dispersion will break, and aggregation and sedimentation take place.

The colloidal system of nanoparticles is generally least stable when nanoparticles are at $\mathrm{pH}_{\mathrm{pzc}}$ [27] in which the SE of $\mathrm{n}-\mathrm{TiO}_{2}$ will be the highest. Nevertheless, the $\mathrm{SE}$ of $\mathrm{n}-\mathrm{TiO}_{2}$ may be higher than that at $\mathrm{pH}_{\mathrm{pzc}}$ under extremely acidic $(\mathrm{pH}$ $<1.0$ ) conditions (Figure 1(c)) because of the high level of IS. High concentration of $\mathrm{H}^{+}$can efficiently compress the electric double-layer on the surface of $\mathrm{n}-\mathrm{TiO}_{2}$, resulting in high SE of $\mathrm{n}-\mathrm{TiO}_{2}$. Thus, the $\mathrm{pH}$ in the remaining $\mathrm{n}-\mathrm{TiO}_{2}$ sedimentation experiments with $\mathrm{KCl}, \mathrm{CaCl}_{2}$, and $\mathrm{HA}$ were adjusted to 7.0 ( \pm 0.1 ) by adding $0.01 \mathrm{~mol} \mathrm{~L}^{-1} \mathrm{NaOH}$ to eliminate the effect of the high $\mathrm{H}^{+}$concentration introduced by the initial $\mathrm{pH}$ of the solution.

The SE values of $\mathrm{n}-\mathrm{TiO}_{2}$ with $\mathrm{KCl}$ and $\mathrm{CaCl}_{2}$ in different IS values are shown in Figures $1(\mathrm{a})$ and $1(\mathrm{~b})$. At $0.01 \mathrm{mM}$ IS of $\mathrm{KCl}$, the SE of $\mathrm{n}-\mathrm{TiO}_{2}$ was about $20 \%$ after $4 \mathrm{~h}$ of sedimentation. This value approximated that in $\mathrm{pH} 7.0$ with deionized water but without inorganic salt (Figure 1(c)) and increased to about $70 \%$ with $100 \mathrm{mM}$ IS. It can be explicated that an increase in IS compresses the electric doublelayer on the surface of $n-\mathrm{TiO}_{2}$ according to the DerjaguinLandau-Verwey-Overbeek theory [28], thereby decreasing the electrostatic repulsion between two particles with the same charge. The energy barrier will then decrease, and the attachment probability becomes closer to unity.

At lower than $0.1 \mathrm{mM}$ IS of $\mathrm{CaCl}_{2}$, the $\mathrm{SE}$ of $\mathrm{n}-\mathrm{TiO}_{2}$ ranged from $20 \%$ to $25 \%$ after $4 \mathrm{~h}$ of sedimentation; this finding was similar to that with $\mathrm{KCl}$. Conversely, 10 times of the IS of $\mathrm{KCl}$ must be applied to obtain the same SE level of $\mathrm{n}-\mathrm{TiO}_{2}$ at IS higher than $1.0 \mathrm{mM}$. It can be demonstrated that divalent ions may be more efficient in compressing the electric doublelayer on the surface of $\mathrm{n}-\mathrm{TiO}_{2}$ than monovalent ions on account of the Schulze-Hardy rule [29]. With respect to charge screening, compared with monovalent ions, divalent ions have a higher charge density and can induce aggregation and sedimentation of $\mathrm{n}-\mathrm{TiO}_{2}$ at lower IS.

The SE of $n-\mathrm{TiO}_{2}$ with $\mathrm{HA}$ in different TOC concentrations are shown in Figure $1(\mathrm{~d})$. At $10 \mathrm{mg} \mathrm{L}^{-1}$ TOC, the SE of
TABLE 3: $\mathrm{SE}$ of $\mathrm{n}-\mathrm{TiO}_{2}$ based on the orthogonal experiment under different experimental conditions.

\begin{tabular}{|c|c|c|c|c|}
\hline \multirow{2}{*}{ Number } & \multicolumn{3}{|c|}{ Experimental conditions } & \multirow{2}{*}{ SE (\%) } \\
\hline & $\mathrm{pH}$ & IS (mM) & $\operatorname{NOM}\left(\mathrm{mg} \mathrm{L}^{-1}\right)$ & \\
\hline 01 & 6.0 & 0.5 & 0.5 & 25.56 \\
\hline 02 & 6.0 & 0.5 & 1.0 & 12.22 \\
\hline 03 & 6.0 & 0.5 & 5.0 & 5.56 \\
\hline 04 & 6.0 & 2.5 & 0.5 & 32.22 \\
\hline 05 & 6.0 & 2.5 & 1.0 & 18.89 \\
\hline 06 & 6.0 & 2.5 & 5.0 & 15.56 \\
\hline 07 & 6.0 & 25 & 0.5 & 57.78 \\
\hline 08 & 6.0 & 25 & 1.0 & 55.56 \\
\hline 09 & 6.0 & 25 & 5.0 & 51.11 \\
\hline 10 & 7.0 & 0.5 & 0.5 & 22.22 \\
\hline 11 & 7.0 & 0.5 & 1.0 & 7.78 \\
\hline 12 & 7.0 & 0.5 & 5.0 & 3.33 \\
\hline 13 & 7.0 & 2.5 & 0.5 & 26.67 \\
\hline 14 & 7.0 & 2.5 & 1.0 & 16.67 \\
\hline 15 & 7.0 & 2.5 & 5.0 & 11.11 \\
\hline 16 & 7.0 & 25 & 0.5 & 48.89 \\
\hline 17 & 7.0 & 25 & 1.0 & 44.44 \\
\hline 18 & 7.0 & 25 & 5.0 & 37.78 \\
\hline 19 & 8.0 & 0.5 & 0.5 & 30.00 \\
\hline 20 & 8.0 & 0.5 & 1.0 & 21.11 \\
\hline 21 & 8.0 & 0.5 & 5.0 & 12.22 \\
\hline 22 & 8.0 & 2.5 & 0.5 & 42.22 \\
\hline 23 & 8.0 & 2.5 & 1.0 & 31.11 \\
\hline 24 & 8.0 & 2.5 & 5.0 & 24.44 \\
\hline 25 & 8.0 & 25 & 0.5 & 65.56 \\
\hline 26 & 8.0 & 25 & 1.0 & 61.11 \\
\hline 27 & 8.0 & 25 & 5.0 & 58.89 \\
\hline
\end{tabular}

$\mathrm{n}-\mathrm{TiO}_{2}$ was lower than $15 \%$ after $4 \mathrm{~h}$ of sedimentation; this value was lower than that in $\mathrm{pH} 7.0$ with deionized water (Figure 1(c)). It can be indicated that NOM can be coated on the surface of $n-\mathrm{TiO}_{2}$ and reduce the aggregation of $\mathrm{n}$ $\mathrm{TiO}_{2}$. It is attributed to the sterical repulsion due to the large molecular structure of NOM.

3.3. Statistical Analysis of $n-\mathrm{TiO}_{2}$ Sedimentation Behavior. A set of designed orthogonal experiment $\left[\mathrm{L}_{27}\left(3^{13}\right)\right]$ with twenty-seven sedimentation tests was conducted. The experimental design consisted of three independent factors and their interactions. Each independent factor included three levels that were set to simulate the water composition of actual aquatic environments. This experiment was performed to investigate the sedimentation behavior of $\mathrm{n}-\mathrm{TiO}_{2}$ with multiple factors and determine the most predominant factor. The results of the tests are shown in Table 3.

To sequence the affecting ability of the three independent factors and their interactions, we performed range analysis. Range analysis is a statistic method that finds out the differences between the maximum and minimum of the average value of target with each factor in different levels. 


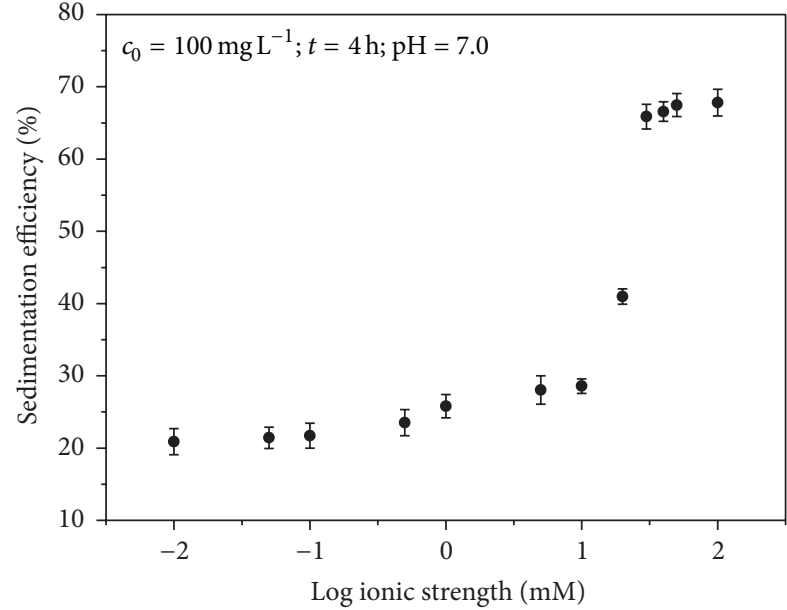

- $\mathrm{KCl}$

(a)

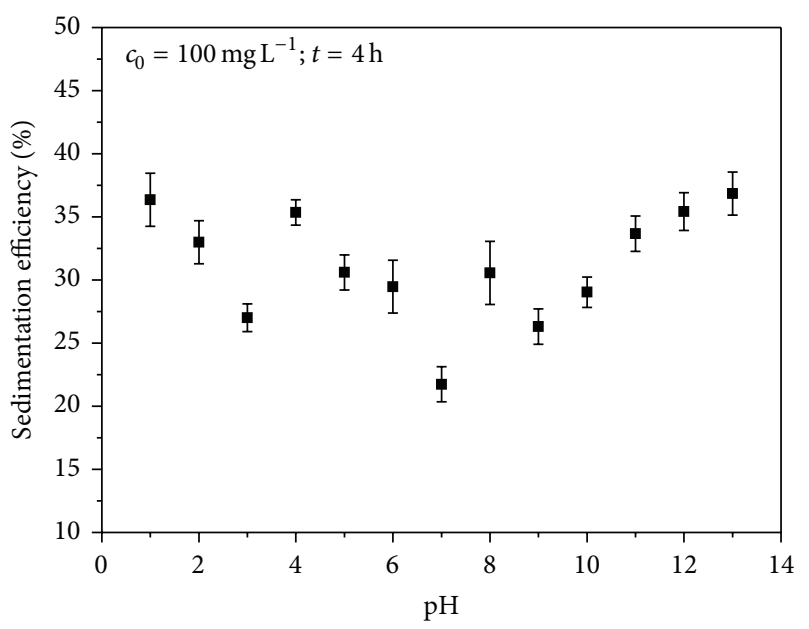

(c)

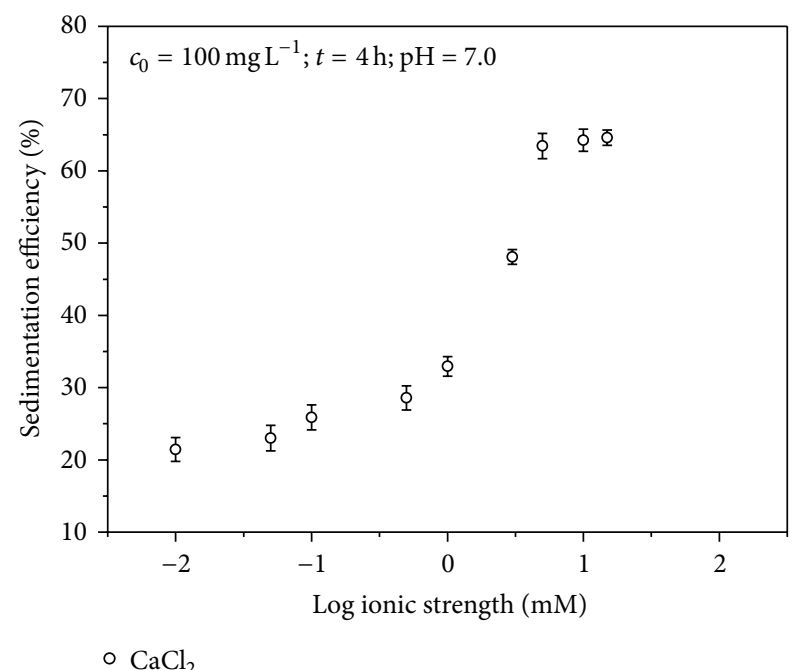

(b)

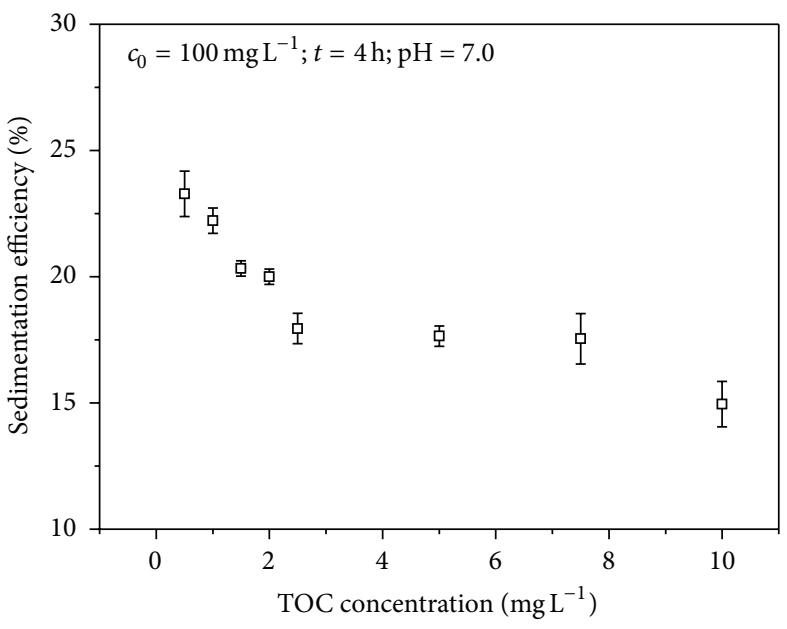

口 HA

(d)

FIGURE 1: $\mathrm{SE}$ of $\mathrm{n}-\mathrm{TiO}_{2}$ with $\mathrm{KCl}(\mathrm{a})$ and $\mathrm{CaCl}_{2}$ (b) in different IS values, $\mathrm{SE}$ of $\mathrm{n}-\mathrm{TiO}_{2}$ in different $\mathrm{pH}$ values (c), and $\mathrm{SE}$ of $\mathrm{n}$ - $\mathrm{TiO}_{2}$ with $\mathrm{HA}$ in different TOC concentrations $(\mathrm{d})$.

By comparing the range difference of factors, we can directly understand which factor may affect the value of target most. The results (details in Table S7) are shown in Table 4. The formula of the range analysis is

$$
R=\max \left[\bar{K}_{1}, \bar{K}_{2}, \bar{K}_{3}\right]-\min \left[\bar{K}_{1}, \bar{K}_{2}, \bar{K}_{3}\right],
$$

where $R$ represents range difference and $\bar{K}_{1}, \bar{K}_{2}$, and $\bar{K}_{3}$ represent the average number of SE with each factor in levels 1,2 , and 3 , respectively.

In this study, the value of target is $\mathrm{n}-\mathrm{TiO}_{2} \mathrm{SE}$ which relates to the sedimentation behavior of $\mathrm{n}-\mathrm{TiO}_{2}$. The factor with the highest $R$ could be considered as the main factor that affects the sedimentation behavior of $\mathrm{n}-\mathrm{TiO}_{2}$. On the basis of the results of range analysis, we could arrange the factors based on their affecting ability and the interactions that affect the sedimentation behavior of $\mathrm{n}-\mathrm{TiO}_{2}$ within the range of
TABLE 4: Results of range analysis.

\begin{tabular}{lc}
\hline Factor & $R$ \\
\hline $\mathrm{pH}$ & 14.20 \\
$\mathrm{IS}$ & 37.90 \\
$\mathrm{NOM}$ & 14.57 \\
$\mathrm{pH} \times \mathrm{IS}$ & 5.31 \\
$\mathrm{pH} \times \mathrm{NOM}$ & 3.58 \\
$\mathrm{IS} \times \mathrm{NOM}$ & 6.42 \\
Error & 2.84
\end{tabular}

${ }^{*} R$ is range difference, and " $x$ " represents the interactions between two factors.

the orthogonal experiment and the observed trend was IS > $\mathrm{NOM}>\mathrm{pH}>\mathrm{IS} \times \mathrm{NOM}>\mathrm{pH} \times \mathrm{IS}>\mathrm{pH} \times \mathrm{NOM}$. 
TABLE 5: Results of variance analysis.

\begin{tabular}{lcccc}
\hline Factor & $S$ & $F$ & FR & Significance \\
\hline $\mathrm{pH}$ & 101.40 & 2 & 107.42 & $* * *$ \\
$\mathrm{IS}$ & 787.43 & 2 & 795.38 & $* * *$ \\
$\mathrm{NOM}$ & 108.41 & 2 & 109.51 & $* * *$ \\
$\mathrm{pH} \times \mathrm{IS}$ & 8.73 & 4 & 4.41 & $*$ \\
$\mathrm{pH} \times \mathrm{NOM}$ & 3.73 & 4 & 1.88 & - \\
$\mathrm{IS} \times \mathrm{NOM}$ & 12.37 & 4 & 6.25 & $* *$ \\
Error & 5.94 & 12 & $\backslash$ & $\backslash$ \\
\hline
\end{tabular}

${ }^{*} S$ is the sum of square of deviations, $F$ is the degree of freedom, and " $x$ " represents the interactions between two factors.

Among these three independent factors and their interactions, IS was the most effective factor that influences the sedimentation behavior of $\mathrm{n}-\mathrm{TiO}_{2}$. Moreover, the effects of the three independent factors were stronger than those of their interactions. In the single factor sedimentation experiment of $\mathrm{n}-\mathrm{TiO}_{2}$, the $\mathrm{SE}$ of $\mathrm{n}-\mathrm{TiO}_{2}$ simultaneously increased with increasing IS of inorganic salt. By contrast, the $\mathrm{SE}$ of $\mathrm{n}-\mathrm{TiO}_{2}$ decreased first and then increased with increasing $\mathrm{pH}$ and TOC concentration of NOM. Thus, the interactions between two factors may counterbalance their effects and present a weaker effect of $\mathrm{n}-\mathrm{TiO}_{2}$ sedimentation behavior than single factor.

The findings of range analysis were confirmed through variance analysis. Variance analysis is a statistic method that analyses the significance of factors influencing the value of target. The results (details in Table S8) are shown in Table 5. The parameter ratio of degree of freedom (FR) was introduced with the following formula:

$$
\mathrm{FR}=\frac{\left(S_{f} / F_{f}\right)}{\left(S_{e} / F_{e}\right)},
$$

where $S_{f}$ and $S_{e}$ represent the sum of square of deviations of factors and errors, respectively, and $F_{f}$ and $F_{e}$ denote the degree of freedom of factors and errors, respectively.

By comparing the FR to the $F$ distribution critical values $\left(D_{\alpha}\left[F_{f}, F_{e}\right]\right)$ in different $\alpha$ values, we can elucidate the significance of each factor. The effect of a particular factor on $\mathrm{n}-\mathrm{TiO}_{2}$ sedimentation behavior was evaluated based on the following criteria: FR $>D_{.001}\left[F_{f}, F_{e}\right]$, extremely significant $(* * *)$; FR $>D_{.01}\left[F_{f}, F_{e}\right]$, relatively significant $(* *) ; \mathrm{FR}>$ $D_{.05}\left[F_{f}, F_{e}\right]$, significant $(*)$; and $\mathrm{FR}<D_{.10}\left[F_{f}, F_{e}\right]$, not significant (-).

With regard to this orthogonal experiment, the following degrees of freedom were applied: single factor, 2 ; interactions between two factors, 4; and error, 12. The $F$ distribution critical values used in this experiment are presented as follows [30]:

$$
\begin{aligned}
D_{.001}[2,12] & =12.97 \\
D_{.01}[2,12] & =6.93 \\
D_{.05}[2,12] & =3.89
\end{aligned}
$$

$$
\begin{aligned}
D_{.10}[2,12] & =2.81, \\
D_{.001}[4,12] & =9.63, \\
D_{.01}[4,12] & =5.41, \\
D_{.05}[4,12] & =3.26, \\
D_{.10}[4,12] & =2.48 .
\end{aligned}
$$

Within the range of the orthogonal experiment, the effects of $\mathrm{pH}$, IS, and NOM content on $\mathrm{n}-\mathrm{TiO}_{2}$ sedimentation behavior were extremely significant. The effect of the interactions between IS and NOM content was relatively significant and that of the interactions between IS and $\mathrm{pH}$ was significant. Only the interaction between $\mathrm{pH}$ and NOM content was not significant.

Considering the results of variance analysis, we confirmed that the effect of independent factor on $n-\mathrm{TiO}_{2}$ sedimentation behavior was stronger than that of their interactions. In particular, the effect of IS on $\mathrm{n}-\mathrm{TiO}_{2}$ sedimentation behavior was the highest. Moreover, the significance of each independent factor and their interactions was consistent with the order of the factors and the interactions influencing the sedimentation of $\mathrm{n}-\mathrm{TiO}_{2}$.

3.4. Further Simulative Sedimentation Experiments of $n-\mathrm{TiO}_{2}$ with IS. In the orthogonal sedimentation experiment, we discovered that IS, NOM content, and $\mathrm{pH}$ were remarkable factors that influence $\mathrm{n}-\mathrm{TiO}_{2}$ sedimentation behavior. Hence, we must elucidate the factor that dominatingly affects the sedimentation behavior of $\mathrm{n}-\mathrm{TiO}_{2}$.

The $\mathrm{SE}$ values of $\mathrm{n}-\mathrm{TiO}_{2}$ with different $\mathrm{pH}$ values and NOM contents at different IS values are shown in Figure 2. At low IS level $(0.12 \mathrm{mM})$, the effect of $\mathrm{pH}$ and NOM content on $\mathrm{n}-\mathrm{TiO}_{2}$ sedimentation behavior was similar to the results of $\mathrm{n}-\mathrm{TiO}_{2}$ sedimentation experiment with single factor. At high IS level $(120 \mathrm{mM})$, the $\mathrm{SE}$ of $\mathrm{n}-\mathrm{TiO}_{2}$ with different $\mathrm{pH}$ values and NOM contents was similar. Moreover, the effects of $\mathrm{pH}$ and NOM contents on $\mathrm{n}-\mathrm{TiO}_{2}$ sedimentation behavior were almost replaced by those of IS.

We concluded that $\mathrm{pH}$ and $\mathrm{NOM}$ content can affect the sedimentation behavior of $\mathrm{n}-\mathrm{TiO}_{2}$ at low IS level because the electric double-layer on the surface of $n-\mathrm{TiO}_{2}$ was not compressed. As IS increased, the cations increased and the electric double-layer on the surface of $\mathrm{n}-\mathrm{TiO}_{2}$ was completely compressed. Hence, the effects of $\mathrm{pH}$ and NOM content on $\mathrm{n}-\mathrm{TiO}_{2}$ sedimentation behavior deteriorated. Consequently, IS governed the sedimentation behavior of $\mathrm{n}-\mathrm{TiO}_{2}$ and gradually became the dominating factor.

In $\mathrm{n}-\mathrm{TiO}_{2}$ sedimentation experiment with single factor, divalent cations can efficiently settle $\mathrm{n}-\mathrm{TiO}_{2}$ compared to monovalent cations. The IS of monovalent and divalent cations is a relevant part of the total IS of a solution. In the orthogonal sedimentation experiment, the ratio of monovalent and divalent cations was fixed at $1: 1$. Further studies must focus on the effect of different ratios of monovalent and divalent cations on $\mathrm{n}-\mathrm{TiO}_{2}$ sedimentation behavior. 


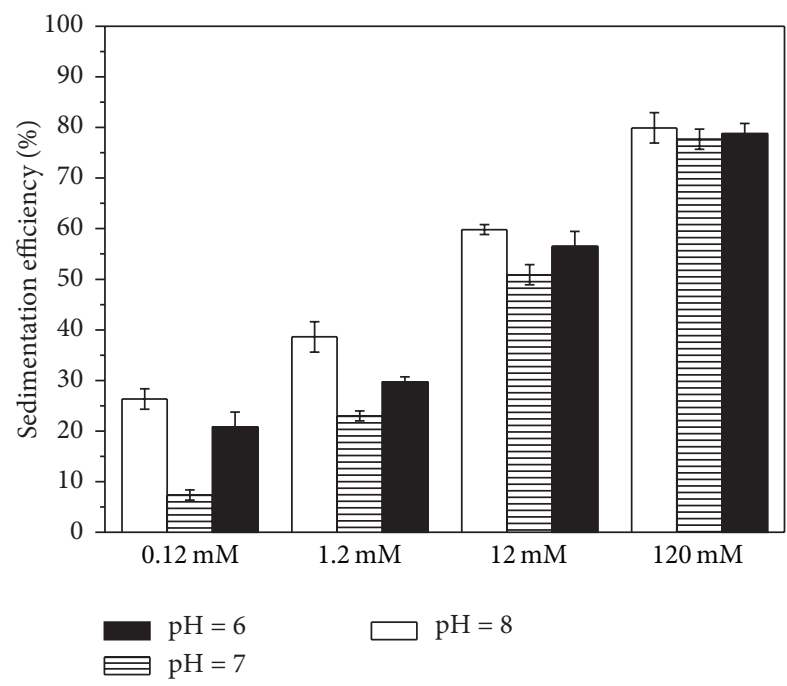

(a)

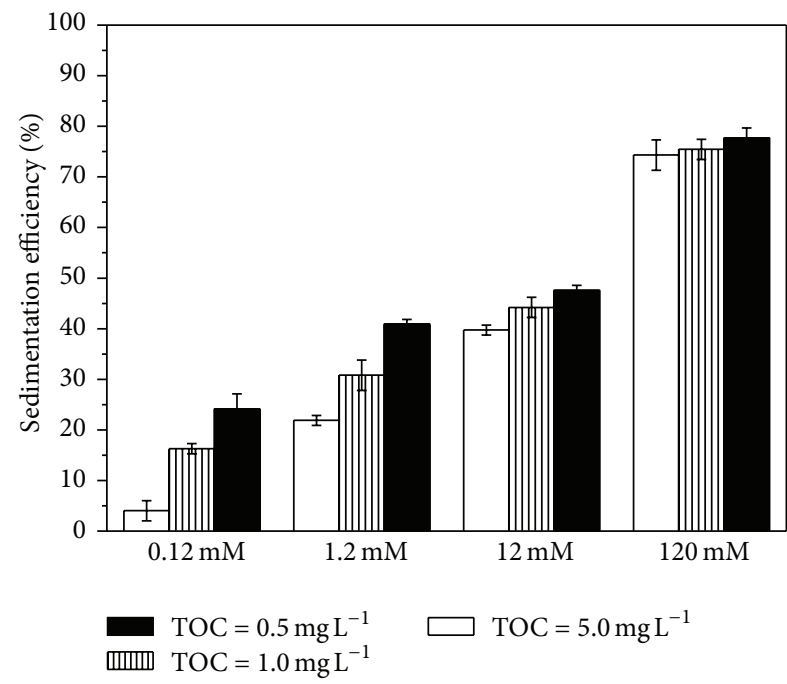

(b)

FIGURE 2: SE of $\mathrm{n}-\mathrm{TiO}_{2}$ with different $\mathrm{pH}$ values at different IS values (a) and SE of $\mathrm{n}-\mathrm{TiO}_{2}$ with different NOM contents at different ionic IS values (b).

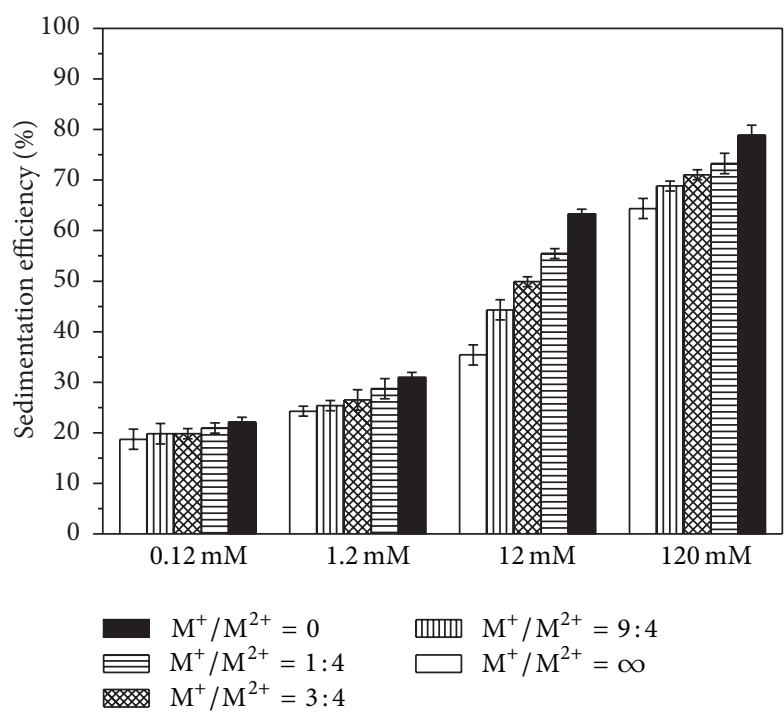

FIGURE 3: SE of $\mathrm{n}-\mathrm{TiO}_{2}$ with different ratios of monovalent and divalent cations at different IS values.

Five different ratios of monovalent and divalent cations were selected in this study, and the results are shown in Figure 3. At fixed total IS of the solution, the high percentage of divalent cations resulted in high SE of $n-\mathrm{TiO}_{2}$. As the total IS of the solution increased, divalent cations can efficiently influence the sedimentation behavior of $\mathrm{n}-\mathrm{TiO}_{2}$. At $0.12 \mathrm{mM}$ total IS, the $\mathrm{SE}$ of $\mathrm{n}-\mathrm{TiO}_{2}$ with pure divalent cations was slightly higher than that with pure monovalent cations. As the total IS increased to $12 \mathrm{mM}$, the SE of n$\mathrm{TiO}_{2}$ with pure divalent cations was twice higher than that with pure monovalent cations. This finding provided a piece of more convincible evidence that divalent ions might be more efficient in compressing the electric double-layer on the surface of $\mathrm{n}-\mathrm{TiO}_{2}$ than monovalent ions.

3.5. Sedimentation Behavior of $n-\mathrm{TiO}_{2}$ in Actual Aquatic Environments. To evaluate the sedimentation behavior of $\mathrm{n}-\mathrm{TiO}_{2}$ in actual aquatic environments, we obtained seven different representative environmental water samples. Four factors were analyzed to determine the relationship between these factors and the SE of $n-\mathrm{TiO}_{2}$ (Figure 4). The IS of the environmental water samples was estimated using seven common ions $\left(\mathrm{Na}^{+}, \mathrm{K}^{+}, \mathrm{Mg}^{2+}, \mathrm{Ca}^{2+}, \mathrm{Cl}^{-}, \mathrm{NO}_{3}{ }^{-}\right.$, and $\left.\mathrm{SO}_{4}{ }^{2-}\right)$, and the results were shown in Table S9. In actual aquatic environments, numerous factors and their interactions may affect the sedimentation behavior of $\mathrm{n}-\mathrm{TiO}_{2}$. Nevertheless, a single factor can be inferred as the dominating factor if its effect on the sedimentation behavior of $n-\mathrm{TiO}_{2}$ is approximately similar to that in actual aquatic environments.

On the basis of the expounded theory above and the results of $\mathrm{n}-\mathrm{TiO}_{2}$ sedimentation experiments with $\mathrm{pH}$, IS, and NOM content, we considered that the factor exhibiting good correlation with $\mathrm{SE}$ of $\mathrm{n}-\mathrm{TiO}_{2}$ could be the dominating factor that influences the sedimentation behavior of $n-\mathrm{TiO}_{2}$ in actual aquatic environments.

NOM content and $\mathrm{pH}$ of the environmental water samples did not demonstrate good correlations with SE of n$\mathrm{TiO}_{2}$ (Figures 4(c) and 4(a)), and their linear correlation coefficients $\left(R^{2}\right)$ were only 0.024 and 0.199 , respectively. In $\mathrm{n}-\mathrm{TiO}_{2}$ sedimentation experiment with single factor, the SE of $\mathrm{n}-\mathrm{TiO}_{2}$ was lowest at $\mathrm{pH}$ of approximately 7.0 and highest with increasing TOC concentration of NOM. The $\mathrm{pH}$ of river water sample was 7.1, which was almost equal to 7.0; hence, the $\mathrm{SE}$ of $\mathrm{n}-\mathrm{TiO}_{2}$ in the river water sample was higher than that in reservoir water sample $(\mathrm{pH}=6.8)$ and tap water sample $(\mathrm{pH}=7.4)$. The TOC concentration of waste water sample was the highest $\left(5.696 \mathrm{mg} \mathrm{L}^{-1}\right)$, but the $\mathrm{SE}$ of $\mathrm{n}-\mathrm{TiO}_{2}$ in this 


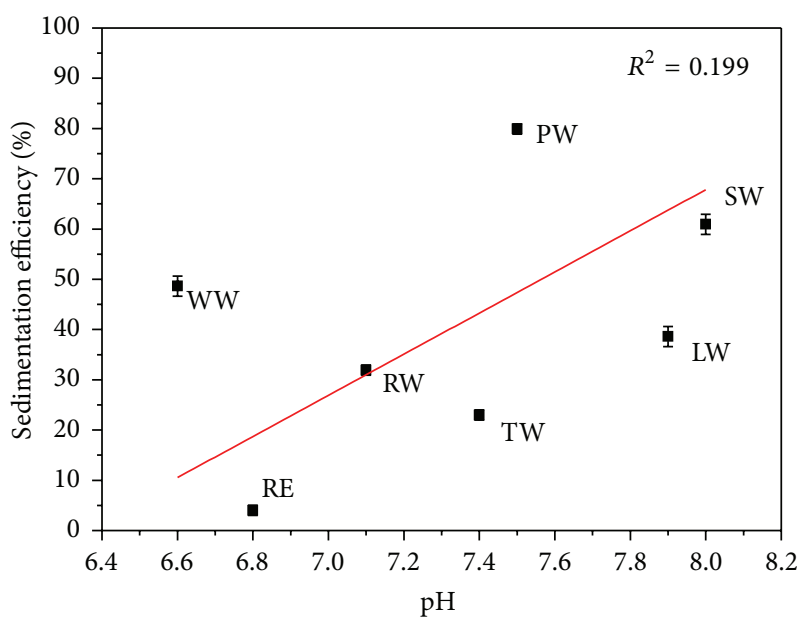

(a)

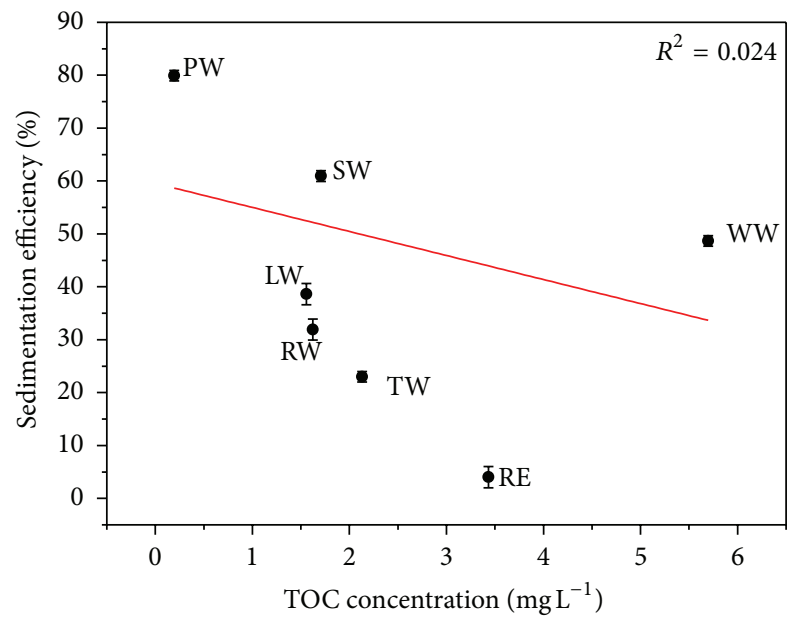

(c)

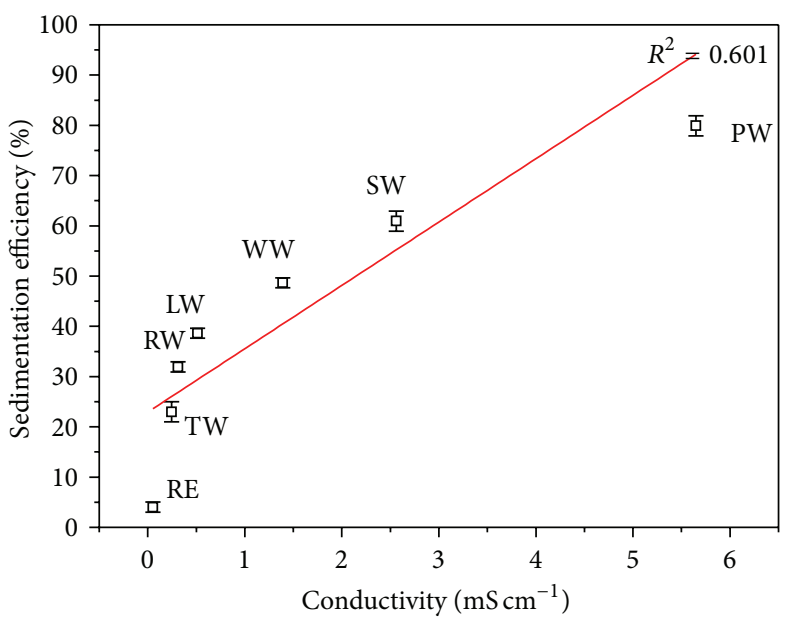

(b)

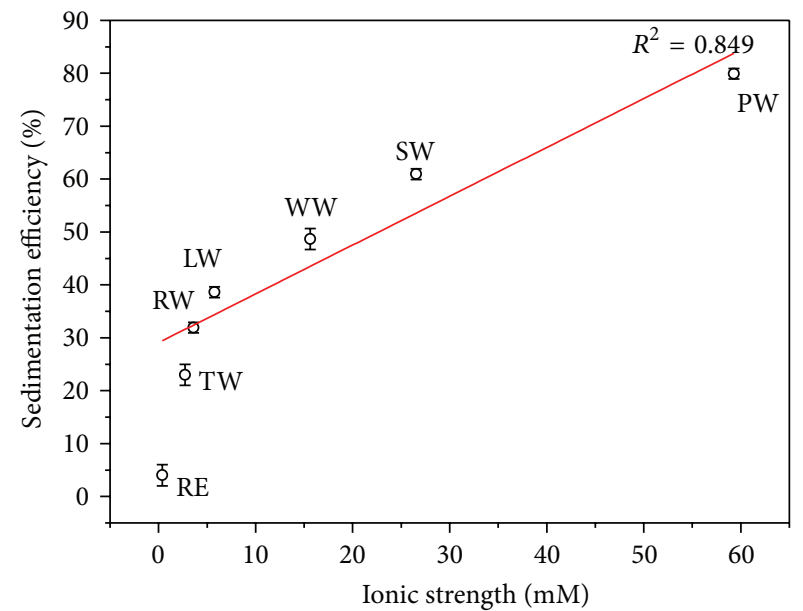

(d)

FIGURE 4: Relationship between $\mathrm{SE}$ of $\mathrm{n}-\mathrm{TiO}_{2}$ and $\mathrm{pH}(\mathrm{a})$, conductivity (b), NOM content (c), and IS (d) of environmental water samples.

sample was higher than those in the other environmental water samples. Hence, $\mathrm{pH}$ and TOC concentrations were not crucial in the sedimentation of $\mathrm{n}-\mathrm{TiO}_{2}$ in actual aquatic environments.

Conductivity exhibited a positive correlation with IS. The IS of environment water samples presented an excellent linearity with SE of $n-\mathrm{TiO}_{2}$ (Figures $4(\mathrm{~b})$ and $4(\mathrm{~d})$ ). The linear correlation coefficients $\left(R^{2}\right)$ were 0.601 and 0.849 , respectively. In $\mathrm{n}-\mathrm{TiO}_{2}$ sedimentation experiment with single factor, the SE of $\mathrm{n}-\mathrm{TiO}_{2}$ simultaneously increased as the IS of inorganic salt increased. This phenomenon was also observed when $\mathrm{n}-\mathrm{TiO}_{2}$ settled in environmental water samples. The IS of phreatic water sample was the highest $(59.29 \mathrm{mM})$, and the $\mathrm{SE}$ of $\mathrm{n}-\mathrm{TiO}_{2}$ in this sample was also the highest. Conversely, the IS of reservoir water sample was the lowest $(0.3740 \mathrm{mM})$ and the $\mathrm{SE}$ of $\mathrm{n}-\mathrm{TiO}_{2}$ in this sample was the lowest. Thus, we concluded that IS was the most vital factor that affects the sedimentation behavior of $n-\mathrm{TiO}_{2}$ in actual aquatic environments.

In $\mathrm{n}-\mathrm{TiO}_{2}$ sedimentation experiment with single factor and multiple factors, we revealed that divalent cations can efficiently influence the sedimentation behavior of $\mathrm{n}-\mathrm{TiO}_{2}$. The relationship between $\mathrm{SE}$ of $\mathrm{TiO}_{2}$ and IS of monovalent and divalent cations in environmental water samples was shown in Figures 5(a) and 5(b). The linear correlation coefficient of the IS of divalent cations with the SE of $\mathrm{TiO}_{2}$ was higher $\left(R^{2}=0.812\right)$ than that of the IS of monovalent cations $\left(R^{2}=0.713\right)$. Accordingly, divalent cations significantly contributed to IS in its dominating role in affecting the sedimentation of $\mathrm{n}-\mathrm{TiO}_{2}$ in actual aquatic environments.

\section{Conclusion}

The main challenge in assessing the sedimentation behavior of nanoparticles is the complexity of actual aquatic environments. Many factors can influence the sedimentation behavior of nanoparticles in actual aquatic environments. Individual determination of the effect of every single factor and their interactions on the sedimentation behavior of nanoparticles in actual aquatic environments is unrealistic and impossible. Hence, the dominating factor must be 


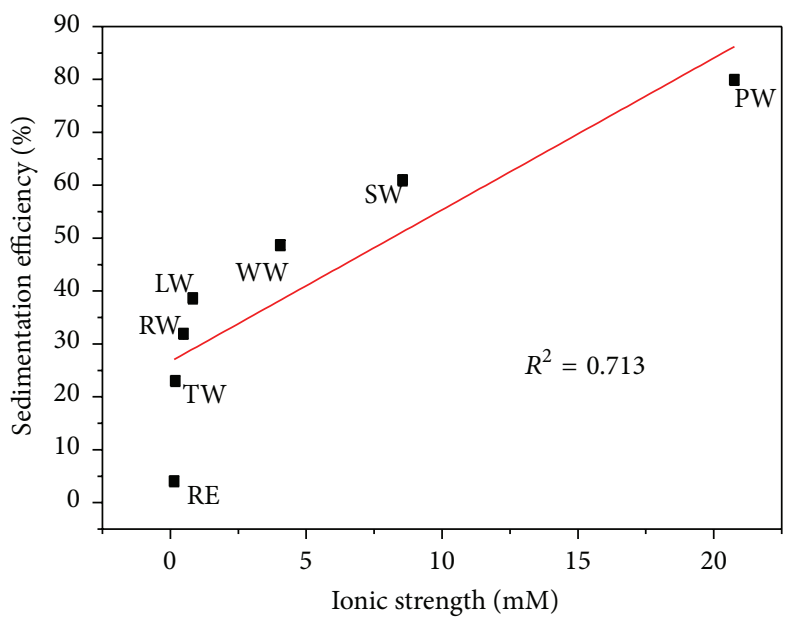

(a)

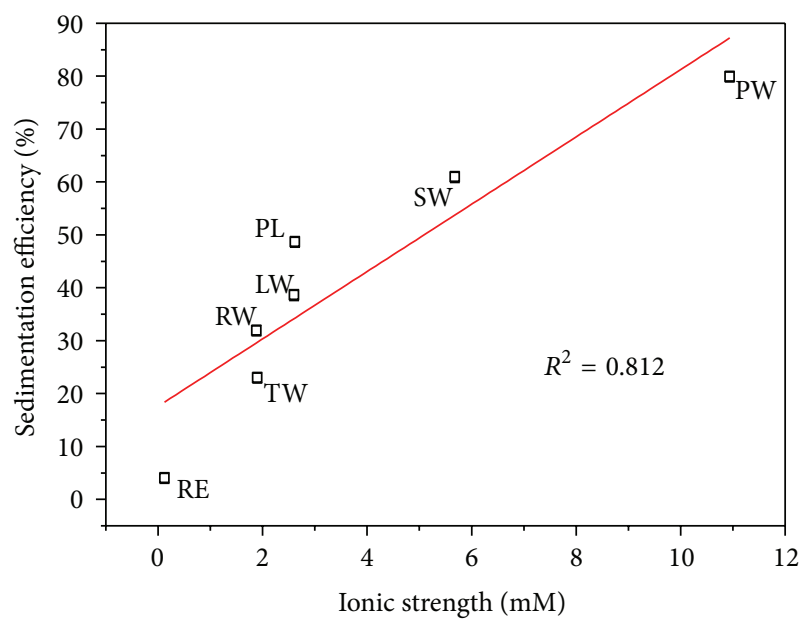

(b)

FIGURE 5: Relationship between SE of $\mathrm{n}-\mathrm{TiO}_{2}$ and IS of monovalent (a) and divalent (b) cations of environmental water samples.

identified because it is crucial in evaluating sedimentation behavior of nanoparticles in actual aquatic environments.

In this study, an orthogonal experimental design was applied to evaluate the sedimentation behavior of $n-\mathrm{TiO}_{2}$. Through range and variance analyses, we statistically found that the IS of water where $\mathrm{n}-\mathrm{TiO}_{2}$ settled played the dominating role in influencing the sedimentation behavior of $n-\mathrm{TiO}_{2}$. This finding was confirmed through sedimentation experiments using environmental water samples. Our findings may simplify assessment of $\mathrm{n}-\mathrm{TiO}_{2}$ sedimentation behavior in actual aquatic environments and provide an opportunity to artificially govern the $\mathrm{n}-\mathrm{TiO}_{2}$ sedimentation process. Thus, we can prevent the uncontrollable dispersion, movement, and transfer of $\mathrm{n}-\mathrm{TiO}_{2}$ in actual aquatic environments and reduce the potential risks of $\mathrm{n}-\mathrm{TiO}_{2}$ to humans and eco-system in the future. By determining the IS, we can easily compare and precisely estimate the sedimentation behavior of $n-\mathrm{TiO}_{2}$ in actual aquatic environments.

\section{Conflict of Interests}

The authors declare that there is no conflict of interests regarding the publication of this paper.

\section{Acknowledgments}

This work was financially supported by the National Natural Science Foundation of China (no. 21067004, no. 51378494, and no. 51378316), Shenzhen Science and Technology Innovation Committee Program (JCYJ20130331151242230), and One Hundred Talents program, CAS.

\section{References}

[1] N. S. Allen, M. Edge, G. Sandoval, J. Verran, J. Stratton, and J. Maltby, "Photocatalytic coatings for environmental applications," Photochemistry and Photobiology, vol. 81, no. 2, pp. 279290, 2005.
[2] I. K. Konstantinou and T. A. Albanis, " $\mathrm{TiO}_{2}$-assisted photocatalytic degradation of azo dyes in aqueous solution: kinetic and mechanistic investigations: a review," Applied Catalysis B: Environmental, vol. 49, no. 1, pp. 1-14, 2004.

[3] G. Balasubramanian, D. D. Dionysiou, M. T. Suidan, I. Baudin, and J.-M. Laîné, "Evaluating the activities of immobilized $\mathrm{TiO}_{2}$ powder films for the photocatalytic degradation of organic contaminants in water," Applied Catalysis B: Environmental, vol. 47, no. 2, pp. 73-84, 2004.

[4] M. M. Higarashi and W. F. Jardim, "Remediation of pesticide contaminated soil using $\mathrm{TiO}_{2}$ mediated by solar light," Catalysis Today, vol. 76, no. 2-4, pp. 201-207, 2002.

[5] J. Yu, M. Jaroniec, H. Yu, and W. Fan, "Synthesis, characterization, properties, and applications of nanosized photocatalytic materials," Journal of Nanomaterials, vol. 2012, Article ID 783686, 3 pages, 2012.

[6] T. Kaida, K. Kobayashi, M. Adachi, and F. Suzuki, "Optical characteristics of titanium oxide interference film and the film laminated with oxides and their applications for cosmetics," Journal of Cosmetic Science, vol. 55, no. 2, pp. 219-220, 2004.

[7] A. Weir, P. Westerhoff, L. Fabricius, K. Hristovski, and N. Von Goetz, "Titanium dioxide nanoparticles in food and personal care products," Environmental Science and Technology, vol. 46, no. 4, pp. 2242-2250, 2012.

[8] A.-P. Zhang and Y.-P. Sun, "Photocatalytic killing effect of $\mathrm{TiO}_{2}$ nanoparticles on Ls-174-t human colon carcinoma cells," World Journal of Gastroenterology, vol. 10, no. 21, pp. 3191-3193, 2004.

[9] J.-R. Gurr, A. S. S. Wang, C.-H. Chen, and K.-Y. Jan, "Ultrafine titanium dioxide particles in the absence of photoactivation can induce oxidative damage to human bronchial epithelial cells," Toxicology, vol. 213, no. 1-2, pp. 66-73, 2005.

[10] W. G. Wamer, J.-J. Yin, and R. R. Wei, "Oxidative damage to nucleic acids photosensitized by titanium dioxide," Free Radical Biology and Medicine, vol. 23, no. 6, pp. 851-858, 1997.

[11] T. C. Long, N. Saleh, R. D. Tilton, G. V. Lowry, and B. Veronesi, "Titanium dioxide (P25) produces reactive oxygen species in immortalized brain microglia $\left(\mathrm{BV}_{2}\right)$ : implications for nanoparticle neurotoxicity," Environmental Science and Technology, vol. 40, no. 14, pp. 4346-4352, 2006. 
[12] D. B. Warheit, T. R. Webb, C. M. Sayes, V. L. Colvin, and K. L. Reed, "Pulmonary instillation studies with nanoscale $\mathrm{TiO}_{2}$ rods and dots in rats: toxicity is not dependent upon particle size and surface area," Toxicological Sciences, vol. 91, no. 1, pp. 227-236, 2006.

[13] G. He, H. Liu, R. Chen, and C. Wang, "Transport behavior of engineered nanosized photocatalytic materials in water," Journal of Nanomaterials, vol. 2013, Article ID 856387, 13 pages, 2013.

[14] J. M. Pettibone, D. M. Cwiertny, M. Scherer, and V. H. Grassian, "Adsorption of organic acids on $\mathrm{TiO}_{2}$ nanoparticles: effects of $\mathrm{pH}$, nanoparticle size, and nanoparticle aggregation," Langmuir, vol. 24, no. 13, pp. 6659-6667, 2008.

[15] R. A. French, A. R. Jacobson, B. Kim, S. L. Isley, L. Penn, and P. C. Baveye, "Influence of ionic strength, $\mathrm{pH}$, and cation valence on aggregation kinetics of titanium dioxide nanoparticles," Environmental Science and Technology, vol. 43, no. 5, pp. 13541359, 2009.

[16] S. Ottofuelling, F. von der Kammer, and T. Hofmann, "Commercial titanium dioxide nanoparticles in both natural and synthetic water: comprehensive multidimensional testing and prediction of aggregation behavior," Environmental Science and Technology, vol. 45, no. 23, pp. 10045-10052, 2011.

[17] A. A. Keller, H. Wang, D. Zhou et al., "Stability and aggregation of metal oxide nanoparticles in natural aqueous matrices," Environmental Science and Technology, vol. 44, no. 6, pp. 19621967, 2010.

[18] R. F. Domingos, N. Tufenkji, and K. J. Wilkinson, "Aggregation of titanium dioxide nanoparticles: role of a fulvic acid," Environmental Science and Technology, vol. 43, no. 5, pp. 1282-1286, 2009.

[19] I. Chowdhury, D. M. Cwiertny, and S. L. Walker, "Combined factors influencing the aggregation and deposition of nano$\mathrm{TiO}_{2}$ in the presence of humic acid and bacteria," Environmental Science and Technology, vol. 46, no. 13, pp. 6968-6976, 2012.

[20] Y. Zhang, Y. Chen, P. Westerhoff, and J. Crittenden, "Impact of natural organic matter and divalent cations on the stability of aqueous nanoparticles," Water Research, vol. 43, no. 17, pp. 4249-4257, 2009.

[21] Y. Jiang, B. Xu, Y. Lü, C. Liu, and M. Liu, "Experimental analysis on the variable polarity plasma arc pressure," Chinese Journal of Mechanical Engineering, vol. 24, no. 4, pp. 607-611, 2011.

[22] H. Deng, G. Zhang, X. Xu, G. Tao, and J. Dai, “Optimization of preparation of activated carbon from cotton stalk by microwave assisted phosphoric acid-chemical activation," Journal of Hazardous Materials, vol. 182, no. 1, pp. 217-224, 2010.

[23] K. L. Chen and M. Elimelech, "Influence of humic acid on the aggregation kinetics of fullerene $\left(\mathrm{C}_{60}\right)$ nanoparticles in monovalent and divalent electrolyte solutions," Journal of Colloid and Interface Science, vol. 309, no. 1, pp. 126-134, 2007.

[24] A. M. El Badawy, T. P. Luxton, R. G. Silva, K. G. Scheckel, M. T. Suidan, and T. M. Tolaymat, "Impact of environmental conditions ( $\mathrm{pH}$, ionic strength, and electrolyte type) on the surface charge and aggregation of silver nanoparticles suspensions," Environmental Science and Technology, vol. 44, no. 4, pp. 12601266, 2010.

[25] R. L. Johnson, G. O. B. Johnson, J. T. Nurmi, and P. G. Tratnyek, "Natural organic matter enhanced mobility of nano zerovalent iron," Environmental Science and Technology, vol. 43, no. 14, pp. 5455-5460, 2009.

[26] J. Fang, X.-Q. Shan, B. Wen, J.-M. Lin, and G. Owens, "Stability of titania nanoparticles in soil suspensions and transport in saturated homogeneous soil columns," Environmental Pollution, vol. 157, no. 4, pp. 1101-1109, 2009.

[27] K. A. D. Guzmán, M. P. Finnegan, and J. F. Banfield, "Influence of surface potential on aggregation and transport of titania nanoparticles," Environmental Science and Technology, vol. 40, no. 24, pp. 7688-7693, 2006.

[28] B. V. Derjaguin and L. Landau, "Theory of the stability of strongly charged lyophobic sols and of the adhesion of strongly charged particles in solutions of electrolytes," Progress in Surface Science, vol. 43, no. 1-4, pp. 30-59, 1993.

[29] W. B. Hardy, "A preliminary investigation of the conditions which determine the stability of irreversible hydrosols," Journal of Physical Chemistry, vol. 4, no. 4, pp. 235-253, 1899.

[30] T. L. VanPool and R. D. Leonard, Quantitative Analysis in Archaeology, Wiley-Blackwell, Oxford, UK, 2010. 

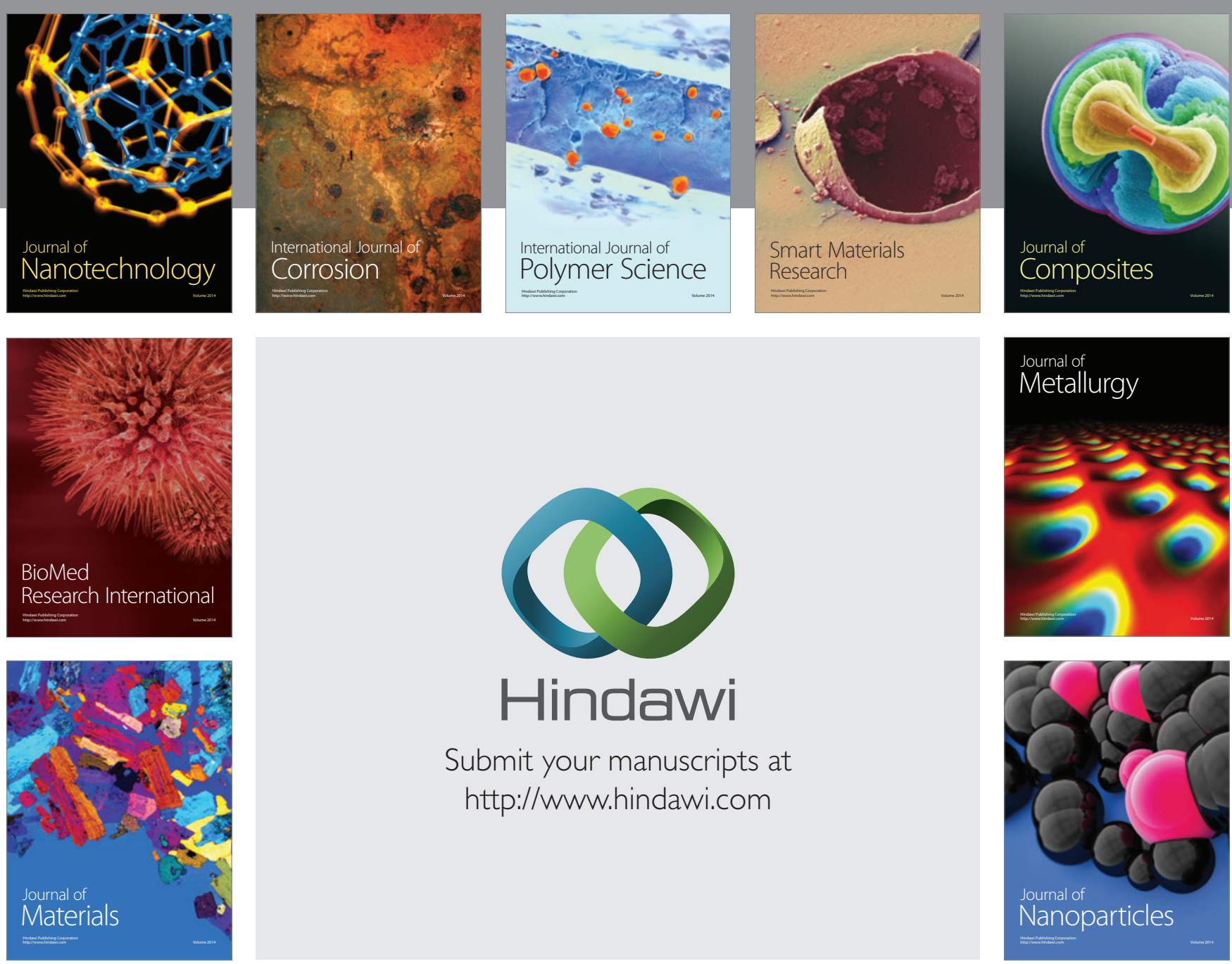

Submit your manuscripts at http://www.hindawi.com
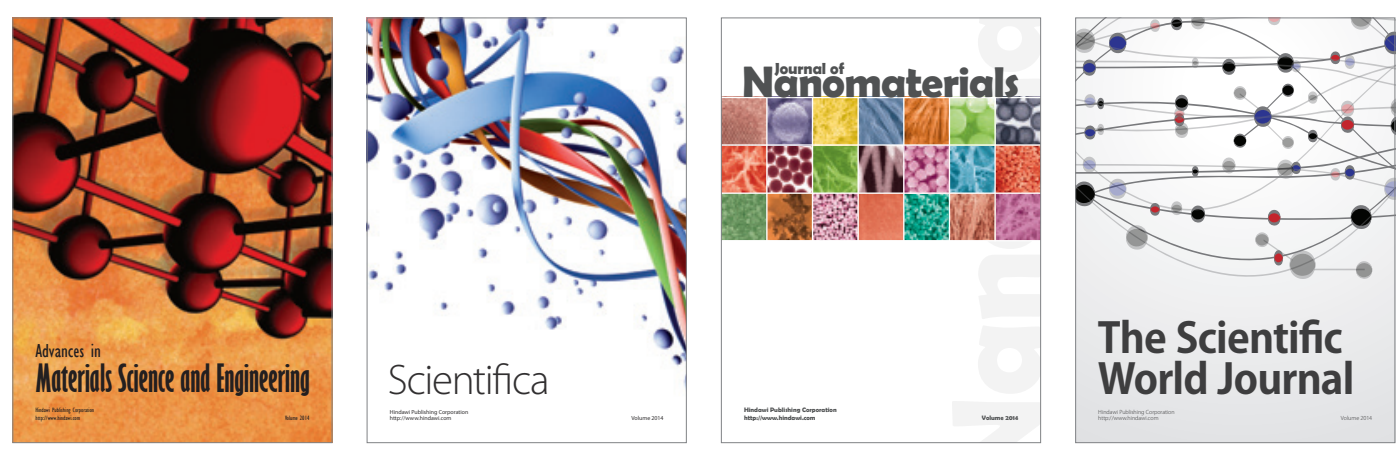

\section{The Scientific World Journal}
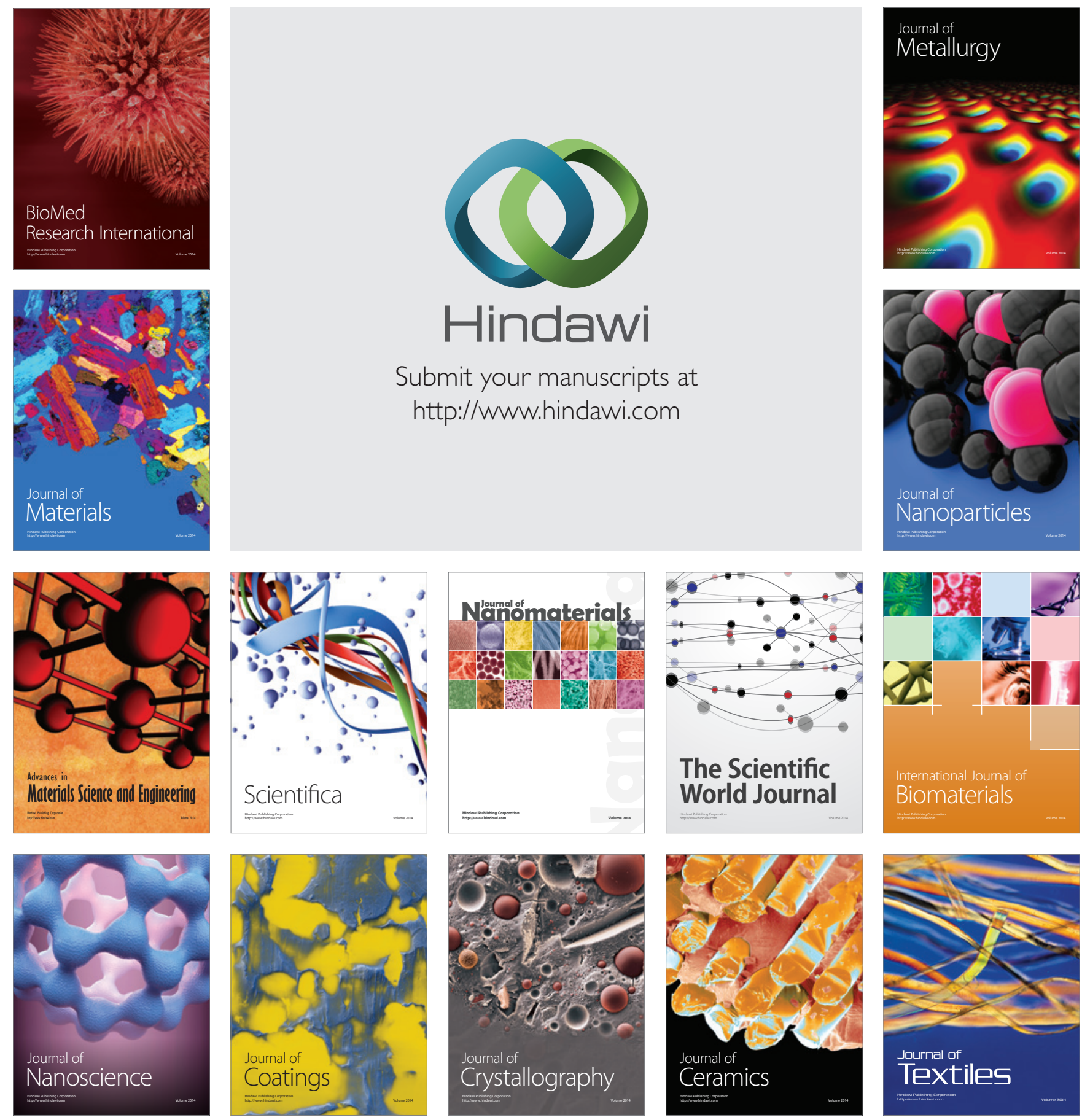